\title{
Effect of Outward Bound Training in Physical Education on Social Adaptation and Mental Health of University Students
}

\author{
Dawei Wan \\ Nanyang Institute of Technology, Nanyang, 473000, China
}

Keywords: Outward bound training, Physical education, Social adaptation, Mental health

\begin{abstract}
The introduction of outward bound training in physical education is the extension of the social function of outward bound training in college physical education, and the innovation of the pursuit of physical and mental health of students in college physical education. Practice shows that the outward-bound training of college sports is helpful to train students' self-care ability, communication ability and teamwork ability. it is also conductive to the cultivation of positive life psychology, confident life attitude and rational life pursuit of university students.
\end{abstract}

\section{Introduction}

In today's rapid economic development, fierce competition has brought great pressure to people, and the quality requirements of people are also increasing. They are not limited to the simple knowledge level. The cultivation of talents focuses more on the cultivation and utilization of human abilities. Comprehensive quality occupies an important position in the process of human development. And outward-bound training has played a certain role in promoting the cultivation of these abilities, and is conducive to the overall improvement of people's overall quality. Outward bound is an extreme sport integrating entertainment and education. Extended training allows participants to exercise after completing a series of activities to achieve unusual experiences, especially psychological ones. The WHO has improved the content of health, pointing out that health should include four aspects of health: physical health, mental health, social adaptability and moral health. Therefore, health does not simply mean physical health, but involves two aspects of the psychological and physiological health. In a narrow sense, development is a kind of team education interaction which integrates management and psychological games into outdoor sports elements. Social education is one of the important content of quality education, is the ability to accumulate a state and social harmony, good adaptability, can endure and overcome difficulties and setbacks, to reduce and eliminate mental pressure, effectively prevent psychological disorders, can be calm in the fierce environment agency, with ease. The social adaptation ability mainly involves the habit of social adjustment ability of college students during school. Mental health refers to the mental state that can maintain stable emotion, keen intelligence and adapt to natural and social abilities in people's life.

\section{Effect of Outward Bound Training in Physical Education on Social Adaptation of University Students}

Cultivate Self-care Ability. With the development of society, the convenience of living conditions and facilities appear, people's lives are becoming more and more convenient, but at the same time, for the new generation, their basic living skills are becoming less and less. A person who can take care of himself must have a comprehensive ability of self-planning, overall planning and self-regulation. Life is a kind of orderly activities, learn to take care of themselves bound to their own daily life, consciously or unconsciously make some plans and arrangements, all abilities will continue to exercise, the ability of college students is the future into the community is necessary, so increase 
the ability to adapt to society in the form of. Open development training course is to enable students to have the place to learn basic self-care ability. The course content can involve not only the family life items such as sewing and cooking, but also the contents of etiquette and other aspects of the job seeking process in the future, which can attract college students in various forms. The combination of development training and community is to enable college students to have the opportunity and occasion to practice and exchange their self-care ability. Community colleges and universities, students can obtain and exercise according to the course content family held a variety of activities and competitions to promote life skills of students, improve students' interpersonal skills, attitude adjustment, will hone; for example, on daily expenditure arrangements, cooking contest, life Almighty, sewing skills and so on. In the extended training stage, everyone is doing the same thing, which provides a good atmosphere for the environment. Outward bound has always been a glorious tradition of hard struggle and self-reliance. The teacher himself provides students with an example of life by themselves.

Cultivate Communication Ability. Training is conducive to cultivating students' good communication skills for communication team, like a nervous system for the human body, is indispensable for the team; communication, control, motivation, emotional expression and information transfer function. Expansion of training programs often set some specific scenarios for students, trainees in the requirements cannot see or hear the case together to complete a task, which requires communication between them with each other to solve the problem, give full play to their language ability and social ability, is conducive to cultivating students' training good communication skills for college students in the future lay the foundation for better survival. Because of the development of quality training, the training programs are specially set up to improve the social adaptability of College students. Only constantly to overcome the fear of fear, in the face of difficulties through their ability to solve, and to actively communicate with teammates, maintain a calm state of mind to face every problem encountered in the training, to fully stimulate the body's energy, to do all the work. This kind of training can effectively improve the communication ability of college students, and help them to know more about the people around them. The university sports development activities training in general consists of a specific scenario, these scenarios are usually simplified form of society in the face of some participants choose to learn and participate in activities when the scene is not only individual behavior, it is related to the collective honor and team. To expand the training to create the environment and the rules of the game, success and setbacks, collaborative competition or constraint in nakedness rules, in the process of situational teaching in interpersonal communication tend to change with the environment and project and the ups and downs of the students' exercise communication ability.

Cultivate Teamwork Ability. In the future, society will not only compete, but also cooperate. Cooperation and competition develop indispensable wings for everyone. A lot of work and tasks must be done by team work and division, and the spirit of teamwork is the most lacking among people, including college students. Team spirit has been fully demonstrated in ground projects. Ground projects have no high level of fear compared with low and medium altitude projects, and are more restricted to certain sensory organs. Expand training can enable students to quickly integrate into the team, the team understands the importance of each role to expand the ice link training is through a few games to break the strangeness between students, narrowing the distance between the students, let students can quickly recognize the strength of the team, and quickly integrate into the team, most willing to pay everything for the team. Each group member has two roles, namely, duty, role and collective role. Job roles are obvious, while collective roles are latent and difficult to recognize. As has been the independent personality of college students, participated in the project experience, attaches great importance to their role in the team, under the leadership of the teachers, the team members with the help of their own, pay more attention to strengthening the consciousness of the role, give full play to the initiative and creative spirit, independent control, control and complete their share task. Through the grid project, students through planning, rational division of labor, make each role, through the cooperation of various roles to success, let students understand that a team is a lot of character form, and each character is very important to establish a successful collective leadership, 
should pay attention to and study the role of the group collocation. Such activities have a high value for the smelting team, and can feel the significance of cooperation.

\section{Effect of Outward Bound Training in Physical Education on Mental Health of University Students}

Cultivate Positive Life Psychology. Outward bound training is conducive to cultivating positive attitude towards life of College students. Positive attitude is a modern man should have the basic quality, but also as one of the core content of a modern personality development training goal is to let students understand, face any difficulties and challenges, we must maintain a positive attitude, positive and optimistic attitude will be the driving force our success, will make our life become more beautiful. Outward bound training allows students to experience good core qualities such as courage, courage, instinct and self-confidence, as well as a positive attitude toward life, such as trust and responsibility. Especially, it can make students experience the whole process of breaking instinct, conquering themselves and building self-confidence. Self-confidence is the core strength of personality. Confident people are cheerful, optimistic, open-minded, and enthusiastic and love life. Confident people are fearless and confident people are happy. Confident people are easy to accept their shortcomings, more objective, more responsible for themselves, life and society full of expectations and initiative. Outward bound can strengthen the analysis, judgement and decision-making ability in the face of complex situations. It can learn to communicate and coordinate well with others, and optimize the interpersonal environment. It can improve personality, develop perseverance, courage, responsibility, honor and positive values, and strengthen and cultivate the cohesion and competition ability of the team. To expand the training fusion discipline system of modern education, psychology, sports through a variety of involved in a variety of natural and artificial facilities in the fresh, ingenious and exciting activities, can help trainees to release pressure of life study and work, adjust the psychological balance. To expand the training ability of self-control training, take time for pressure and challenge. Outward bound training can strengthen the spirit of exploration and innovation, and cultivate initiative.

Cultivate Confident Life Attitude. When the students through the efforts to overcome the difficulties, overcome the original thought of physical and psychological difficulties and obstacles to overcome, the completion of a dangerous action, will feel the hitherto unknown sense of accomplishment. The student's complete development training project of dangerous action in the process of practice, to overcome the fear, to overcome the self, the purpose is to let students understand a truth: in the face of difficulties and maintain peace of mind to fully trust their own ability, believe they will be able to overcome the existing difficulties, overcome self-success. The development of training programs and the form of the formation of the psychological, intellectual and physical strength of the formation of a certain and even severe test. Each trainee in the challenge and overcome the self-belief driven by their potential is fully tapped, creativity has been most incisive play, especially to the contemporary college students, learning and life are relatively smooth, the lack of difficulties, will relatively weak, once suffered setbacks, often depressed, even unable to get up after a fall. Only constantly to overcome the fear of fear, in the face of difficulties through their ability to solve, and to actively communicate with teammates, maintain a calm state of mind to face every problem encountered in training. If you work hard, you can do as well as others. To bravely try those seemingly impossible things, their potential is to be explored in a bold attempt, which has a positive effect on College Students' self-awareness and evaluation. Outward bound teaches them to break through individual mental disorders, do not deny themselves easily, and do not always give themselves bad hints. Everyone has a great ability and rich resources, not just never know their abilities, bravely jumped out of the first step, success is not far away. Outward bound training can help the students to evaluate themselves correctly and build good self-confidence and self-evaluation ability, which is a self-awareness activity with a strong emotional experience. Outward bound training is an experiential learning style, and it is also a process of cultivating self-confidence. 
Cultivate Rational Life Pursuit. Outward bound training is helpful for college students to establish a rational life and expand training programs. By setting up unusual challenge scenarios, trainees are arranged to participate in projects that seem difficult, and finally, collective organizations share insights. Participating in development training not only can relieve the psychological pressure of college students, but more importantly, through the project challenges, can accurately locate the life, clear their pursuit of life. Outward bound training not only expands the hearts and minds of college students, but also helps to establish their ideal and pursuit of life. Outward bound training can not only improve the mental health of college students, but also promote the cohesion of the class. The enhancement of class cohesion can provide a good environment for the development of College Students' mental health. The teaching experiment results show that the expansion in the improvement of College Students' psychological health advantages, and points out that the physical education in Colleges and universities to expand the training content into a new way to improve the quality of college students, but also conform to the needs of physical education reform in the new period. To expand the training, by setting the scene for challenges, challenges, organizational perception sharing, so that students in a particular environment, to receive psychological test; in the offbeat challenges, stimulate their own potential; in a team atmosphere, and constantly improve the understanding, can not only relieve the psychological pressure, the more important is through project challenges after feeling, giving top priority to straighten out the positioning of life, the pursuit of. When sharing feelings, college students talk about not only my life, but frustration and pressure. Even the wisest and most successful people suffer the same misfortune and failure. Without hard struggle, there will be no brilliant success. Without success, caring for my relatives, educating my teachers and caring for my own society. Outward bound training not only expands the psychological quality of college students, but also expands their ideal and pursuit.

\section{Conclusion}

Outward bound training program is an emerging item in college physical education. It is characterized by promoting psychological quality and social adaptability in experiential activities. There is no doubt that outward bound can improve students' psychological quality. Outward bound is a comprehensive activity which integrates education, sports, psychology and social function, and physical fitness, psychological quality and social adaptability are indispensable in outward bound training. Outward bound training is a useful attempt to carry out quality education in an all-round way.

\section{References}

[1] Zhou Zikai. Difficulties and Countermeasures of Outward Bound Training in College Physical Education [J]. Bulletin of Sport Science \& Technology, 2017, 25(4): 86-87.

[2] Bi Yonggang. Analysis of the Rol e of Outward Bound Training in College Physical Education [J]. Journal of Puer University, 2016, 32(3): 47-49.

[3] LI Yang. Analysis on the application Of outward bound training in colleges and universities teaching [J]. Academic Journal of Shaolin and Taiji (Zhongzhou Sports), 2013(5): 43-45.

[4] Tang Min. Function of Outward Bound Sports in College Physical Education Teaching [J]. Bulletin of Sport Science \& Technology, 2015, 23(1): 71-73. 